\title{
La Filosofía y el Problema Moral.
}

No es lo único ni lo principal el problema del ser, considerado abstractamente, clentro del conjunto de temas que usualmene trata la filosofía. La filosofía se pregunta también, con intenso y renovado interés, qué es la existencia, cuál es la forma de ser que le es propia; cuál es la manera o maneras que adopta el ser redily determinado, cuyo tipo más completo se nos muestra en la existencia del hombre. El saber filosófico no sólo se dirije al examen y captación de motivos lejanos a la realiclad y a la vida, ni pretende ser siempre un mero ejercicio de la actividad intelectual. Se interesa tambiéß poriel seceoncretoetreas por el ente, es decir por la manjfestacióncon mainifestacienes positivas y determinadas del ser, por lo que constituye la vida misma en sus más acusađas determinaciones. Asi abandona la filosofía su posición de disciplina técnica, indiferente y neutral, y se convierte en emocionada exégesis de la vida misma del hombre.

Ante todo hay que tenery en cuenta la pregunta referente a lo que es el ser humano, la cual tuna vez contestada puede servir como fundamento utilísimo a la ética. La ética tiene en esta forma un fundamento metafísico apropiado y también un fundamento antropológico. No cabe hacer elocubraciones acerca de lo que debe ser, si no se to- 
ma en cuenta seriamente lo que es la naturaleza humana. Una ética fundada en principios ajenos en absoluto a lo humano sería una elaboración intelectual ilusoria, una fantasia, o un conjunto de preceptos estériles.

En todas las épocas se encuentra subyacente nuna concepción de lo humano, aunque no se haya configurado en forma precisa una antropología filosófica, ni haya llegado a constituirse una filosofía de la existencia humana. Tal concepción puede deducirse del examen de los diversos elementos de la cultura artística, religiosa, intelectual, jurídica y política. Al fin y al cabo el hombre es el sujeto y la materia de todas las relaciones, puesto que ninguna se puede dar ni comprender sin su intervención. Por otra parte debe tenerse presente que las diversas modalidades de la cultura, incluso la misma modalidad ética que estamos estudiando, son maneras proplas y earacterísticas de la existencia humana, fuera de la cuál carecen de sentido. Cuando se comprenda profundamente y se le confiera todo su alcance a la posición central de to humano en el planteamiento

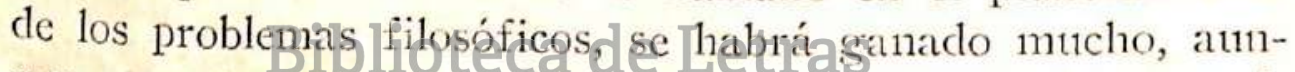
que por otra parte se pjerclan Cunchas elocubraciones estériles sin raices en el suelo de la realidad.

Para los griegos, el hombre no se contrapone a los demás objetos de la naturaleza, entre lo natural y lo humano no existe para ellos una precisa línea divisoria. Los mismos principios que sirven para la interpretación de la naturaleza, sirven para la interpretación del hombre. De esta stierte, el pensamiento griego alcanza un plano de armonía, entre el hombre y la naturaleza. El único dualismo violento que se destaca con relativa constancia en el pensamiento de los griegos es el de lo real y lo icleal, que los grandes pensadores intentaron siempre conciliar. Así se 
observa en las obras de Platón y de Aristóteles. El primero trata de hacer comprensible la conexión entre el devenir y el mundo de las ideas, gracias a la intervención de un demiurgo intermediario, dotado de profundos sentimientos artísticos. Desde luego, natural no es lo mismo que material. La naturaleza, según los griegos, estaba integrada por un principio material, el cual se configuraba gracias a la intervención de principios naturales, pero no materiales. Una clara confirmación de lo que decimos se encuentra en el pensamiento de los estoicos, quienes formularon como principio de su filosofía el vivir conforme a la naturaleza, entendienclo por naturaleza la razón. Los epicúreos interpretaron lo humano en idéntico senticto, por medio de principios naturales. En efecto, la búsqueda del placer como valor supremo de la vida humana, es la confirmación de su anhelo de someterse a principios naturales. El placer traduce la espontaneidad del ser que vive de acuerdo con sus inclinaciones.

En la Edad Media se interpreta al hombre en oposición a la naturaleza, en vista de su destino y de su esencia religiosa. El hombre se qibera de $1 \mathrm{a}$ - naturaleza para unirse más intimamente conr ge Biffipladi Genyentido del hombre no se encuentra ya en la tierra, en el mundo, ni en principios ideales o racionales; Dios da al hombre su sentido; si no fuera por El, el hombre no existiría; puesto que E1 constituye la finalidad y la dignidad del hombre, sin las cuales la humanidad volvería al nivel de la naturaleza. En cierto modo, aunque el hombre no es esencialmente divino, participa de la naturaleza de Dios en cuanto ha sido creado por Este. Su vida en el mundo es un residir pasajero, un pasar por un amargo valle de lágrimas; al cabo del cual es posible encontrar la verdadera patria y la verdadera felicidad. 
Con el renacimiento se inician sentimientos de hostilidad al Medioevo y a la interpretación del hombre que le era peculiar. Desde luego debe rechazarse de paso la idea de que el renacimiento es un movimiento independiente y extraño a la Edad Media. Agudas observaciones y estudios sobre esta época de la Historia Humana, ponen de manifiesto que no existe aquella solución de continuidad entre la Edad Media y el Renacimiento, que se ha quericlo ver principalmente con un afán de crítica negativa con respecto al Medioevo. Los primeros movimientos renacentistas aparecen en el seno de la misma Edad Media, tanto en el orden artístico como en el político y económico. La burguesía misma que caracteriza como forma social y económica a la Edad. Moderna, aparece en la Europa Medioeval del siglo XIII, en la medida en que se iban relajando o desintegrancto las formas sociales y económicas de la Europa feudal y caballeresca de los siglos anteriores. Así el Renacimiento aparece no como una manifestación súbita de cultura, sino como la culminación de un movimiento que había estada preparán-

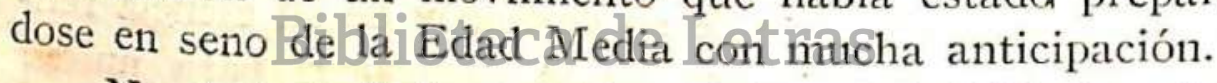

No obstanterdabercnacidbi en pleña Edad Media, el Renacimiento se presenta en aparente contradicción con ella. Se inicia en medio de sentimientos hostiles y críticos frente a la cultura Medioeval. Quiere independizarse de ella, romper las limitaciones impuestas por la religión y la escolástica, abrir nuevas rutas en el mundo, promover el amor y el conocimiento de la naturaleza. En una palabra el hombre vuelve a asombrarse en la contemplación del mundo y en la de sí mismo. Su mayor preocupación es la vuelta a la naturaleza. Entonces Dios se convierte en un principio ajeno al mundo, el cual se explica por sí mismo o por medio de principios humanos y racionales. Un renacentista tan preclaro 
como Miguel de Montaigne expresa en su pensamiento el anhelo de aproximar la interpretación del hombre a la naturaleza. No obstante su elegante escepticismo, que se expresa en su fórmula Que sais'je, sostiene la necesidad de rebajar la imágen del hombre, exaltada por la presunción y el falso orgullo, hasta el plano de la naturaleza. Así, entre ei hombre y los animales no hay una diferencia esencial. En el fondo esta concepción de lo humano campea también en el racionalismo que pretende interpretar el universo por medio de la razón. El siglo de las luces consagra la razón como la explicación única y decisiva de todo. En esta forma, y aparentemente, el hombre trata ce escapar a la naturaleza, deja de ser el haz de apetitos que fué el hombre del Renacimiento, para convertirse en un ente racional superior a sus propios impulsos. En el siglo de las inces, el hombre alcanza el plano más elevado de su orgullo; convencido de que la razón le brinda explicaciones para todo y que al mismo tiempo ha encontrado el fundantento de su más elevada dignidad. Sin embargo, la realiđad era muy diversa. Por debajo de los excesos del Bảcibinalismog seeincubabans los gérmenes disolventes irracionalistaspy deraterialistaselEb,siglo XIX es el siglo de las explicaciones irracionalistas y vitales. La noción de vida hace su ingreso triunfal en la filosofía; y en la política habían irrumpido revolucionaria y victoriosamente las masas, que en sí misma constituyen la representación de lo desmesurado y lo irracional, ya desde fines del siglo XVIII. En un mundo nuevo, tenían que surgir nuevas maneras de pensar. Stirne, Schopenhauer, Nietzsche, Marx, Engels, Darwin y otros representan, a pesar de la diversidad personal de su pensamiento, la misma dirección, el mismo sentido irracionalista de la existencia. No se piense que el siglo XIX no trae aportaciones positivas a la concepción 
de lo humano. Irracionalismo y vitalismo no son pura negación; ni aún las tendencias económicas y las mismas interpretaciones materialistas dejan de responder al interés general humano. Precisamente el siglo XIX resume una gran inquietud en torno a las cuestiones humanas. El escepticismo filosófico y la propensión a colocar en primer plano los impulsos, nos hacen pensar en una humanidad mucho más concreta que la que era familiar al indiviclualismo. La concepción del hombre, ya sea en las doctrinas de Nietzsche, en el positivismo de Comte o en los nuevos programas revolucionarios, revela una honda inquietud por lo humano integral, por el individuo que se supera en el plano social. El XIX es siglo humanitario por excelencia; por eso nace en él la sociología, y la psicologia se vuelve ciencia inclependiente. La historia asume la dignidad de ciencia espiritual y la justicia en las relaciones económicas y sociales se hace agudo problema para los gobiernos. Pero tal humanitarismo no podía contenerse en los limites estrechos de lo individual; por el contrario, la consigna es la superación del individuo. La concepcioni individualistal burgutesaque había tenido su raiz a fines "de la misman Edad Media dy que se encontraba subyacente en la Edad Moderna, alentando tanto los movimientos intelectuales como los políticos, hace su crisis en el siglo XIX. El hombre no es un individuo aislado, ni un átono irreductible; ni la sociedad puede ser un mero agregado de partículas individuales. Lo humano sobrepasa los límites de lo individual; en otros términos el hombre como individuo que se basta a si mismo es realmente una ilusión. Lo primordial y lo básico para el siglo XIX es la sociedad. Ni aún Federico Nietzsche, ferviente partidario del individuo y enemigo acérrimo de las tendencias socialistas, por considerarlas contrarias a la exaltación de los supremos valores del in- 
dividuo, se mantuvo dentro de los límites de ló individual. Nietzche propugnó también la superación del individuo en su teoría del Super-hombre (el hombre no es sino un puente entre el hombre y el superhombre, así hablaba Zarathustra). Las virtudes del superhombre le permiten a éste colocarse en una situación superior a la del mero individuo. Si bien es cierto que la teoria del Superhombre no fué suficientemente esclarecida por Nietzsche, queda como principio indiscutible que en él intenta Nietzsche expresar su anhelo de vencer la mezquindad y la limitación impuesta históricamente por la mediocre concepción del individuo.

Más resueltamente se manifiestan las tendencias antiinclividualistas en el positivismo de Augusto Comte y en el socialismo Marxista. El primero reivindica la prioridad de lo social; dirije su atención sobre tos fenómenos de estática y la dinámica de las sociedades funda en esta forma la sociología. Es posible que el nacimiento de la sociología sea uno de los acontecimientos más trascendentales para la cultura del siglo XIX. En otra época hubiera sido inconcebible; pero en el siglo XIX obedecia a una necesidad, respondia a una exigencia del sentido mismo de la cultura. La sociología aparece para proclamar la crisis del individualismo. La sociedad se presenta entonces como un hecho real, no como el producto de una simple relación voluntaria entre individuos, no como contrato, ni como hecho jurídico o cultural, es decir no como artificio ni creación espontánea del hombre. Tradición, historia, fuerzas vitales internas, constituyen el origen y el fundamento firme de la vida social. El positivismo, en Comte o en Spencer, reivindican la importancia decisiva de los hechos reales en el proceso de la evolución humana. En el fondo de todo ello hay un arraigado 
sentimiento anti-indiviclualista, una concepción orgánica de la existencia y una inclinación a insertar la inágen del hombre en el curso de los hechos reales.

Otra de las manifestaciones culturales contrarias al individualismo es el socialismo de Carlos Marx, quien tuvo el acierto de señalar la importancia de los fenómenos económicos en la organización social. Es imposible actherir a la tesis materialista sostenida por Marx; y desde luego al materialismo como explicación económica de los hechos históricos. El hombre no es un simple haz de impulsos y de apetitos; en él se encuentra la sede de complejas necesidacles. No es verdad por otra parte que lo económico determine siempre la conducta de los hombres y de los pueblos. Las circunstancias de que en todas las épocas y en todos los momentos de la historia humana encontremos fenómenos de inclole económica, que se estremezclan con los diversos fenómenos culturales de otra especie, no significa que lo económico sea la razón decisiva de los demás. No hay que olvidar que con este criterio podríano'sefácilmente encentrar asidero a cualesquiera teorías para la explicación dedos hechos históricos. 'Así como encontramos fenómenos económicos, encontramos también políticos, religiosos, artísticos, biológicos, los cuales pueden ser utilizados para la explicación unilateral de lo histórico con igual legitimidar que los fenómenos económicos. Así se podría fundamentar un estetisísmo histórico, un politisísmo, un providencialismo, etc. Nadie puede negar que el fenómeno económico acompaña siempre a los fenómenos histórico-culturales. Un artista, un sacerdote, un hombre de ciencia son seres humanos integrales; además sus actividades se relacionan en buena parte con los intereses que defiende su clase. Pero todo esto no es suficiente para sos- 
tener que la creación artística, la obra científica y las plegarias del sacerdote obedecen a razones de utilidad, de ventaja o de lucro personal o social. Sobre todo el arte y la ciencia se nos presentan como actividades puras, desprovistas de todo mezquino interés. Cuando éste aparece dentro de las obras artísticas o de cualquier otra índole, la crítica se encarga inmediatamente de ubicar la obra respectiva en la categoría inferior que le corresponde; o por lo menos de distinguir el arte puro de sus bastardos acompañantes en los que se traduce el interés personal o el prejuicio económico clasista.

Nuestros días viven bajo el signo irracionalista, a pesar de los esfuerzos muy meritorios del Neokantismo, que dominó en gran parte el cạnpo filosófico europeo hasta la guerra de 1914. Se obserwa tambien un -elativo retorno a las posiciones de la antiguiedad. La metafísica ha vuelto a ser la ocupación esencial; mas no en la dimensión intelectualista y abstracta, sino como dirección-antropológica, como preocupación por el hombrejy por su destino La metafísica de hoy quiere llegar a una interpretacion del ser a partir del ser humano finito.

Quién mejor ha estudiado estos problemas es Martín Heidegger. Según él, el único ser capaz de dar respuesta a la pregunta ¿Qué es el ser?, es el hombre, el ser humano finito. Sólo el ente humano (Dasein puede revelarnos el ser, es decir su propio ser, del cual ya tiene una noción os-. cura (dunkle Seinsverstandnis), y cuyo sentido se prefigura en la misma pregunta por el ser. La particular manera que reviste el ser en el hombre, o en otros términos la forma concreta y temporal del ser es el existir. La vida humana es existencia, transcurrir entre dos incertidumbres, la del ori- 
gen y la del fin, surgir de la nada y concluir en la muerte que es también la nada. La filosofía de la existencia es, de esta suerte, una filosofía de la vida, aunque de fondo irracional, sin embargo orientada hacia la delimitación y claridad en los conceptos. Sus orígenes se encuentran en la discusión del problema del hombre, motivo predilecto del siglo XIX. Además Heidegger intenta revalorizar elementos de la antigua metafísica. Para la indagación y elaboración de sus problemas, utiliza el método fenomenológico.

Heidegger estudia al hombre en su desenvolvimiento, discriminando grados o modalidades de su ser. El hombre comienza por un estar en el mundo, y en este sentido el ser del hombre es ser en el mundo (Das in-der-Welt-Sein). De este modo el mundo no es algo totalmente ajeno al hombre, es una posibilidad del hombre misuzo. No puede haber hombres sino el mundo. Ser hombre es ser "alli", en el mundo. $\mathrm{Y}$ frente a este mundo, el hombre no tiene una actitud de conocimiento, sino de simple enlace o contacto. Es como si el hombre estyyileråosemetido en [urar expa densa y oscura. En esta etapa g grado ethombre tiendea protegerse, lo domina la preocupación, el miedo, el temor de recibir algún daño. La murmuración le infunde mayor temor aún; le preocupan y le desconciertan las opiniones de los demás. Su propio mundo es el mundo común a los demás. En realidad para él es este un mundo impropio, en el cual el hombre no puede revelar el perfil más característico cle su personalidad, se limita a ser un hombre como los otros hombres. Es lo que Heidegger llama Das Man, el se, el uno cualquiera, carente de determinaciones individuales y lejos de la intimidad de su propia esencia.

Liego el hombre se clescubre así mismo, a la existen- 
cia impropia, sucede la existencia propia. El hombre va a lo íntimo de sí mismo, se apropia de sí mismo. Ahora 10 acompaña la angustia, que no es el miedo que podía dominar al hombre de la existencia impropia. La angustia es una ansiedad y una especie de tranquilo temor. El hombre es un ser espiritualmente angustiado; parece como que sintiera en su conciencia el peso de alguna culpa cometida. Y cuanto más penetra en sí mismo, cuanto más libre se siente o se cree, tanto más se asienta en él aquella angustia.

Cuando, al fin, el hombre se enfrenta a los grados supremos de su realización y desenvolvimiento, que son también los de su extinción definitiva, cuando el hombre queda frente a la muerte, y por lo tanto su conocimiento de la vida se vuelve más profunclo, su angustia es mayor, Angst vor dem Tode).

El hombre se diferencia pues del animal, no por el principio de la razón, no por el conocimiento abstracto, que es una modalidad stperficial de su ser, sino por estados afectivos intensos, los cuales tienen su más elevada expresión en la angustia.

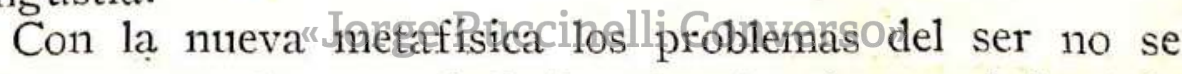
plantean ya en el campo de lo imaginario, sino en el dominio del ser concreto, del ente más concreto y que por lo mismo está por encima đe todos los entes: la existencia humana.

Esta breve exposición de la filosofía de la existencia, hace pensar en la necesidad de buscar las raíces de los hechos éticos en lo más entrañable de la elocubración metafísica. La descripción que acabamos de hacer, pone de manifiesto la imposibilidad de separar las cuestiones éticas de las metafísicas. La naturaleza humana es un ente sensible a los valores y vive en relación constante con el mundo, realizando diversas formas de valoración; al mismo tiempo trata de 
superar los grados inferiores de su existencia y de lograr los stuperiores. Es inconcebible suponer la existencia de una viđa humana desprovista de nociones acerca del deber y del valor, una vida ajena a los conflictos éticos, carente del anhelo de superación. Y lo que es más, estas manifestaciones de la vida humana tienen su fundamento en la naturaleza misma de nuestro propio ser. He allí la valiosa contribución de la metafísica a la solución teórica de los problentas éticos; y lo que hace aún más meritoria la filosofía de Heidegger, es el hecho de presentarnos no una abstracción, sino la imagen real y viviente del ser humano. En efecto, no todo el hombre es un "ser asi", ni un "ser esto o aquello". No todas las cuestiones que podemos plantearnos respecto a su ser, se pueden expresar en la forma de un "que es" o de un "como es". En otros términos, lo humano real no es todo lo humano. El hombre está en fo real, frente a lo real y en cierto modo es lo real; pero también está frente a lo irreal. Deberes, valores, principios, normas son entidacles irreales. Lo futuro mismo es

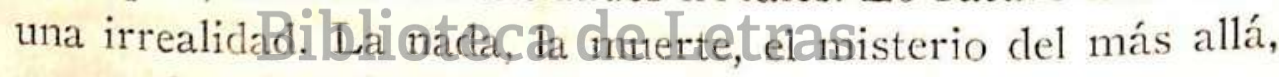
son motivos ijroadespuxechbbinbelpereibe, intuye o comprende, y cuya evidencia en mayor o menor grado, determina las formas generales de su conducta, precisamente lo real en el hombre es vivir en contacto con lo irreal, en relación con valores, deberes, normas. El acatamiento, o la desobediencia a tales realidades irreales conștituyen la más intensa y la más significativa realidad de la vida humana.

Así, de la consideración del problema de la existencia del hombre surge espontáneamente el problema del "hacer". Qué debemos hacer en la existencia, es la cuestión básica de la ética filosófica, a la que intentamos responder, expresa o tácitamente, en el transcurso de estas lecciones. 
Si la existencia tiene tal configuración, si la vida del hombre se encuentra sometida a tales determinaciones y tiene tales atributos, la conducta deberá estar regida por determinados principios, y no por otros. Este es el problema que interesa específicamente a la ética en cuanto ciencia filosófica de la conducta. Desde luego, no intentamos definir aquí apriori en qué consiste la conducta ética. Sólo una intensa familiaridad con las cuestiones que aborda ésta ciencia, nos pondrá en condiciones de comprender sin dificultad la naturaleza especial de la conducta que hemos determinado de antemano como conducta ética.

De lo dicho resulta que la investigación de lo que debemos hacer va precedida y debe dar en to principal por resueltas diversas cuestiones metafísicas ygr., un repertorio de los problemas de la existencia del hombre enfocados ontológicamente, la descripción y explicación de los diversas clases de objetos que se dan a la conciencia, una teoría del conocimiento de los valores, teoría de la persona, etc. La cuestión ética se plantea entonces así: en virtud de que el hombre se encuentra, en st existencia real, frente a.

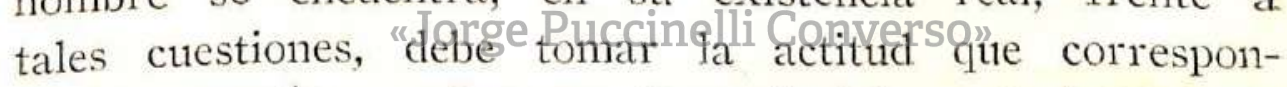
de $y$ proceder conforme a los principios que lo pongan en relación con la entidad misma que constituye sus problemas. Un fundamento distinto para la ética, es equivocado y carece de eficacia y de autoridad para solicitar nuestra adhesión. Descartamos desde ahora la posibilidad de fundamentar la ética en sí misma, en principios específicamente éticos. Una autonomía absoluta de la ética deja planteada siempre la pregunta con respecto a los fines últimos y supremos. Descle luego rechazamos también la pretensión de fundar la ética en hechos reales, en fenómenos, en hábitos, en 
costumbres. Pretensiones de esta índole revelan claramente el desconocimiento absoluto de la intimidad de los problemas éticos. La dimensión en la que se producen los hechos a que se refiere la ética es la dimensión cle la espiritualidad. En ella los hechos ciertamente son acogidos y estudiados, pero a condición de que se desentrañe su sentido. Más importante es éste que el hecho mismo. Puede decirse aún que en la ética el hecho se identifica con el sentido. La forma de realización es adventicia, se exterioriza según las circunstạncias, y en algunos casos no llega a exteriorizarse, ya sea porque encuentra resistencias en las circunstancias materiales o sociales, ya sea porque estas resistencias provienen de la misma constitución caracterológica de los individuos. Por algo interesan a la etica las intenciones y en algunos casos las disposiciones mismas, es decir, lo que está cletrás đe las intenciones. Por otra parte lo que importa no es el hecho. Un ejemplo sensible, que aclara esta cuestión hasta la evidencia, lo tenemos en la caridad. El acto de ofrecer un auxilio a la persona que nos lo solicita, puede constituir caridad, puede ser el resultado de profundos sentimientos de amor a nuestros semejantes; y puede explicarse también por vanidad, por ostentación, por costumbre $y$ hasta por egoísmo.

Si desplazamos el problema de la relación entre la metafísica y la ética al campo de lo psicológico, nos encontramos con la cuestión que consiste en discriminar lo que se debe a la actividad teorética y a la práctica. Es evidente que la metafísica implica en el sujeto el desarrollo opuesta en acción de la actividad teorética; mientras que la ética implica la realización de la actividad práctica. En esta forma no se puede dar solución acertada a las cuestiones que nos 
plantea la ética; porque no es posible admitir la posibilidad de diversas modalidades de ética, esencialmente distintas entre sí. Pero tampoco se puede prescindir de una alusión siquiera al campo psicológico, a la constitución caracterológica de los individuos. En realidad las diversas modalidades de la constitución caracterológica, condicionan matices más o menos acentuados en la actitud y en la conducta ética; sin llegar a constituir diferencias radicales en cuanto a la esencia misma del fenómeno ético. La tradición del artista se califica éticamente de la misma manera que la tradición del sabio. La pureza o la inocencia del hombre sencillo valen lo mismo que cuando se presentan en mentalidades superiores, complicadas o estilizadas por la cultura. Por eso, la distinción que ha realizado el filosofo italiano Benedetto Croce, es admisible sólo desde el punto de vista empírico, como elegante distingo fenomenológico; pero no como base para una distinción radical, que nos precipitaría en el escepticismo. En la realidad, las esferas de lo teorético y lo práctico se complementan, se entrecruzan, se refuerzan recíprocamente. Un hombitelieatescal hismo tiempo teorético y

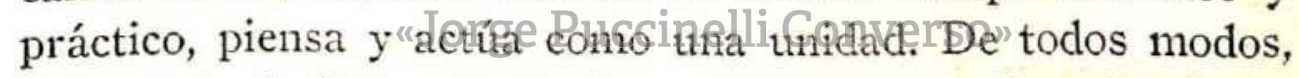
vale, como decimos por su elegancia y por su belleza, la distinción de Croce. "Una mirada a la vida que nos circunda dice- parecería, sin necesidad de particular demostración, más que suficiente para revelar la realidad de un círculo de actividad práctica que se desenvuelve al lado de la teorética. En la vida se ven casi materialmente distintos a los hombres de pensamiento y a los hombres de acción, a los contempladores y a los operadores; a este lado, frentes amplias y ojos tardos y soñadores; al otro, frentes estrechas y ojos movibles y vigilantes. Poetas y filósofos a un lado. Al 
otro, capitanes y soldados, de la industria, del comercio, de la política, de la milicia, de la Iglesia. Y como los hombres aparecen diversas sus obras. Mientras nos encontramos interesados en un anunciado descubrimiento de química o de física, o en una filosofía que viene a conmover viejas creencias, o en un drama, o en una novela que comportan un nuevo sueño artístico, súbitamente nos interrumpen y llaman nuestra atención espectáculos de muy distinta naturaleza: una guerra entre dos Estados a golpes de cañón y de tarifas aduaneras; una huelga colosal en la que millares de trabajadores hacen sentir al complejo social lo que valen por su número y por su fuerza y lo gue su obra significa en el conjunto de la obra común... El hombre de acción siente repugnancia, de vez en cuando, frente a la orgía de sus esfuerzos volitivos y mira con enviclia al hombre del arte $y$ de la ciencia... Pero también el hombre contemplativo experimenta en ocasiones la misma repugnancia y la misma aspiración; y le parece estar ocioso donde tantos trabajan y sangran, y grita a los combatientes: ¡Dádme armas! y quisiera volverse minero con los mineros, navegante con los

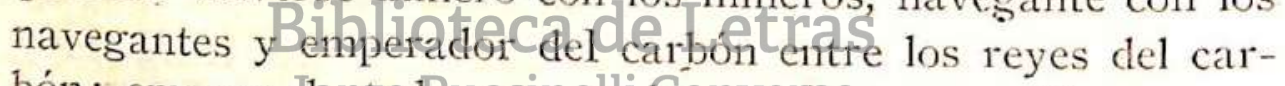
bón: emperor dergedbuestinaldi haedmatso que un libro o una bella canción'.

La misma descripción empírica de Croce nos muestra el enlace entre ambas formas de actividad, la necesiclad que tienen ambas de completarse mutuamente. En el ser humano real, como se ha dicho, lo teorético y lo práctico se dan unidos, aunque en diversa forma, claro está, según el tipo caracterológico respectivo. Así lo práctico del sabio es diferente de lo práctico del político, sin que pueda decirse que lo teorético no exista en el político ni que lo práctico sea desconocido por el hombre de ciencia. El estudio detenido de los diversos tipos caracterológicos que ha hecho Eduardo 
Spranger, nos muestra claramente las diferentes formas que asume lo teorético y lo práctico en los cliferentes tipos humanos.

Con esto volvemos al sujeto real y viviente de la investigación ética; el hombre, cuya comprensión debe intentarse desde un punto de vista integral. En otra forma obtendremos de él una imagen mezquina, que puede ser natural. Sólo la visión de conjunto puede conclucirnos a la interpretación adectrada del ser humano total, de ese ser débil ilimitado en el tiempo, que descle el plano de su "infinita pequeñez", para usar la expresión Pascaliana, se eleva hasta la dignidad absoluta del que participa del clominio de lo absoluto, hasta la conciencia de quien realiza valores eternos y aún hasta la certeza y el asombro de quien descubre nuevas regiones de lo valioso.

La diafanidad de la conciencia ética no es permanente en la historia. Así se explican las crisis, los fenómenos de desorientación moral de lastumanidad y desde luego la formación de sistemas éticos erróneos. Precisamente el hombre moderno estBibledotocradadie turatépara de desorien-

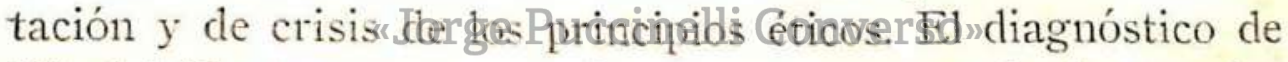
Nicolai Hartmanu es muy interesante, por venir de tan alta y esclarecida mentalidad: "El hombre moderno, dice, no es solamente el que se apresura sin tregua; es también el embotado, el indiferente a quien nada eleva, interesa o llena interiormente. Para todo tiene una sonrisa de ironía o de cansancio. Para él es una virtud su estado de depresión moral. Su incapacidad para admirar, para sorprenderse, para entusiasmar, para respetar, es levantada por él hasta el plano de un hábito vital permanente y querido. El deslizarse indiferente sobre todo es un cómodo modus vivendi. Así le agrada a él encontrarse en la pose del que está enci- 
ma de todo, y oculta en esta forma el vacío que se encuentra en su interior. Este pathos es típico. No aparece hoy en la historia por primera vez. Pero siempre que ha aparecido ha sido un síntoma de debilidad y de decadencia, del fracaso interior y del pesimismo general de la vida".

A pesar del gravísimo contenido de verdad que encierra las aseveraciones de Hartmann, no debemos arribar a una conclusión pesimista y negativa. Las perspectivas de la cultura no están-como muchos han creído-agotadas. Hay siempre nuevos caminos que explorar y nuevos valores que descubrir y afirmar. No se puede llamar decadencia de la cultura a la mera imposibilidad de afirmar algunos valores tradicionales. En medio de la quiebra de valores consagrados por el respecto de muchas generaciones, van surgiendo nuevos y fecundos valores humanos, prestigiados por su vitalidad por sus virtualidades para satisfacer las nuevas exigencias que se presentan. Ni aún los conflictos armados, como ya se ha visto en anterior oportunidad, han conseguido extinguir y agotar la sabia de la cultura occidental. No podemos creer que la iulturasedencuentreareducida a las obras đe arte y a laşocindadesciuellsé destenyen por efectos de la lucha armada. Hay algo más que los hombres no alcanzan a descubrir en el breve lapso que dura la lucha y algo que por su naturaleza misma se encuentra al margen de los peligros, de las contingencias y de los desvaríos morbosos de la humanidad. Además la especie đe hombre a que se refiere Hartmann no es el hombre actual: es el hombre ya viejo y sin esperanzas, el hombre del siglo XIX, cuya mentalidad flota todavía hecha trizas, en esta hora, quizás solamente para enseñarnos que la historia es una trama contínua, que la voluntad humana no puede interrumpir.

Enrtoue Barboza. 